\title{
Weedy fallow as an alternative strategy for reducing nitrogen loss from annual cropping systems
}

\author{
Sam E. Wortman ${ }^{1}$ \\ Accepted: 22 September 2016/Published online: 20 October 2016 \\ (C) INRA and Springer-Verlag France 2016
}

\begin{abstract}
Nitrogen loss from croplands is a major environmental problem with human health and ecosystem consequences. Cover crops are planted during the fallow period between cash crops to provide a number of ecosystem services and are a popular tool for nitrogen reduction. Unfortunately, on-farm adoption of cover crops in the USA is limited to less than $2 \%$ of land area in most regions. Naturally occurring weeds, if left unmanaged between cash crops (i.e., "weedy fallow"), may provide similar ecosystem services (e.g., nitrogen reduction) as cover crops. To test this hypothesis, a metaanalysis of 17 studies was conducted to compare potential nitrogen loss (inorganic soil nitrogen or leachate nitrogen) from fallow annual cropping systems managed with cover crops, weeds, and bare soil. A potential nitrogen loss response ratio (e.g., leachate nitrogen from bare soil relative to weedy fallow) was determined for independent paired observations in each study, and factors influencing nitrogen loss across all studies were determined with $95 \%$ bootstrap confidence intervals and meta-regression analysis. Results suggest that potential nitrogen loss from croplands is $60 \%$ greater in bare soil compared to weedy fallow fields. Cover crops further reduced potential nitrogen loss by $26 \%$ compared to weedy fallow, and the nitrogen reduction potential of cover crops (relative to weedy fallow) likely increases with greater biomass accumulation of the cover crop. While cover crops were more effective in mitigating potential nitrogen loss, weedy fallow may provide greater net benefits on a regional scale if there were fewer barriers to farmer adoption. The weedy fallow strategy for nitrogen reduction has several potential pitfalls (e.g.,
\end{abstract}

Sam E. Wortman

swortman@illinois.edu

1 Department of Crop Sciences, University of Illinois at Urbana-Champaign, 1201 S Dorner Dr., Urbana, IL 61801, USA propagation of noxious or herbicide-resistant weedy species), but this meta-analysis demonstrates that fallow weeds provide an important ecosystem service and policy-makers should consider revising conservation incentive programs accordingly.

Keywords Cover crops · Conservation agriculture $\cdot$ Nitrogen leaching $\cdot$ Water quality $\cdot$ Winter weeds

\section{Contents}

1. Introduction

2. Meta-analysis methods

2.1. Article search and selection criteria

2.2. Data extraction and analysis

3. Results and Discussion

3.1. Weedy fallow and cover crops reduce potential nitrogen loss

3.2. Increasing vegetative biomass may reduce potential nitrogen loss

3.3. Options for increasing the benefits of weedy fallow

3.4. Limitations of weedy fallow

3.5. Policy implications and potential impact of weedy fallow

4. Conclusion

\section{Introduction}

Nitrogen fertilization is an essential management practice in plant-based agriculture, but the loss of nitrogen from croplands via leaching and volatilization is a significant environmental problem (Di and Cameron 2002; Xing and Zhu 2000). Inorganic nitrogen fertilizer, in addition to nitrogen mineralized 
from soil organic matter, lost from agroecosystems in the Mississippi River basin (MRB) of the USA contributes to hypoxia in the Gulf of Mexico and the contamination of domestic water supplies (Burkart and James 1999; Power and Schepers 1989). Nitrogen losses have been accelerated in recent years due to a concurrent increase in artificial drainage of agricultural fields (e.g., tile drainage) and the number of corn (Zea mays L.) acres in the MRB (David et al. 2013).

Several management and regulatory strategies are currently being used to reduce nitrogen loss from croplands, particularly in the MRB. Some of the common strategies include changes to fertilizer management (e.g., rate, timing, and placement); the use of nitrification inhibitors and tile bioreactors; conversion of sensitive cropland to constructed wetlands, buffer strips, perennial crops, or into the US Department of Agriculture (USDA) Natural Resources Conservation Service (NRCS) Conservation Reserve Program; and the use of cover crops (David et al. 2013). Each strategy has benefits and drawbacks, but cover crops have received increased attention from farmers as a nitrogen reduction tool (Myers and Watts 2015), in part because this strategy is relatively inexpensive, does not typically require valuable cropland be removed from production, and may provide a number of other agronomic benefits (Snapp et al. 2005). Winter cover crops can reduce nitrogen leaching by as much as $80 \%$ compared to bare soil (Staver and Brinsfield 1998; Wyland et al. 1996), but effectiveness depends on many site-specific soil, climatic, and management factors. Cover crop adoption is increasing every year in the MRB, but barriers to adoption include cover crop establishment, seed cost, and the additional time and labor required to manage the cover crop (Myers and Watts 2015). Despite the potential for reducing nitrogen loss, cover crops are used on less than $2 \%$ of total cropland area in the MRB and nutrient pollution of groundwater and the Gulf of Mexico is not decreasing (Bryant et al. 2013; David et al. 2013).

While cover crops are helpful, the severity of this environmental problem demands further exploration of strategies for reducing nitrogen loss from croplands. One potential strategy, not dissimilar from cover cropping, is the natural regeneration and growth of ambient weeds between cropping cycles (hereafter called "weedy fallow"; Fig. 1). While this strategy has received comparatively little attention from researchers and regulators, its use (intentional or not) can be observed each spring in fields of the MRB filled with white (Thlaspi arvense L.), purple (Lamium amplexicaule L.), and yellow (Sinapis arvensis L. subsp. Arvensis) flowers (Fig. 2). Although weedy fallow is likely more common than cover crop use in the MRB (e.g., greater than $2 \%$ of cropland area), it is not typically recognized as a formal nitrogen reduction strategy. This lack of recognition may be due at least in part to a complexity of social factors (e.g., stigmas and negative attitudes toward the utility of traditionally weedy species), but there has also been limited science-based information and discussion about the effectiveness of weedy fallow as a nitrogen reduction strategy. The reluctance to consider weedy fallow as an approach to nitrogen reduction may be related to the potential pitfalls of this strategy, which could include the possibility for future crop-weed interference (direct and indirect) in diversified rotations and the proliferation of noxious weed species or herbicide-resistant populations. However, if fallow weeds do provide significant ecosystem services, it may be possible to explore management options for mitigating any potentially negative side effects or pitfalls of the weedy fallow strategy.

Quantifying the potential for weedy fallow to reduce nitrogen losses has important policy, economic, and environmental implications for stakeholders in the MRB and elsewhere. Therefore, the objective of this meta-analysis was to compare potential nitrogen loss from annual cropping systems between crop cycles (e.g., winter) when soil was managed bare, as weedy fallow, or with cover crops. Weedy fallow, as it is currently practiced, requires little to no farmer time, labor, or money, which are all significant barriers to cover crop adoption; in the absence of these barriers, weedy fallow may have greater potential for widespread adoption and net nitrogen reduction, even if the strategy is not as effective as cover crops (or other nitrogen reduction strategies) on a per area basis.

\section{Meta-analysis methods}

\subsection{Article search and selection criteria}

The influence of fallow period soil management on actual or potential nitrogen losses from cropland was estimated via systematic literature review and meta-analysis of data from this literature. Two literature searches were conducted by using the Scopus search engines (Elsevier). The first search, targeted toward nitrogen leaching losses from croplands, returned 37 total results and included the terms "cover crop," "green manure," or "catch crop," and "leaching," "nitrogen," and "weed" in the title, abstract, or keywords. To increase the pool of possible studies, the search was broadened to target inorganic soil nitrogen present after the fallow period (as a measure of potential nitrogen loss) in a second search that included the terms "cover crop," "green manure," "catch crop," and "nitrogen," "nitrate," or " $\mathrm{NO}_{3}$," and "weed" in the title, abstract, or keywords. This search returned 262 possible papers. Search results were then reviewed to identify the presence or absence of meta-analysis criteria. For inclusion in the metaanalysis, studies included (1) a measure of potential nitrogen loss during (i.e., leachate nitrogen) or at the conclusion (i.e., inorganic soil nitrogen) of a fallow period in annual croplands (this included most grain and vegetable crops but excluded most forages, cellulosic bioenergy crops, and tree fruits) and (2) a comparison of at least one planted annual cover crop treatment and a weedy fallow treatment that did not receive 


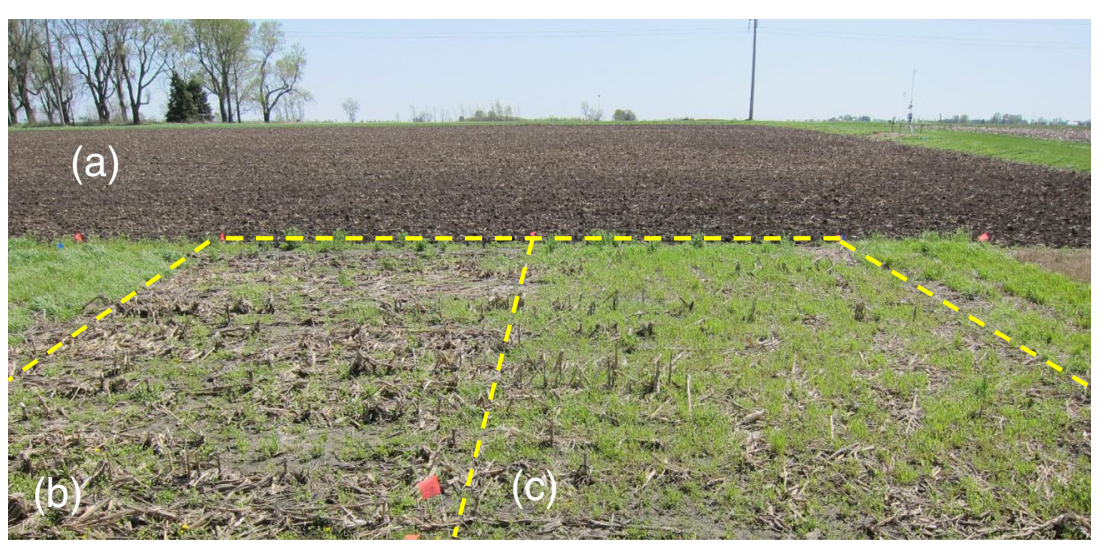

Fig. 1 Comparison of three possible winter fallow management options in croplands of the Mississippi River basin including fall tillage and bare soil fallow (a), weedy fallow (b), and a cereal rye (Secale cereale L.) cover crop (c). Photo taken in mid-April 2015 at the University of Illinois South Farms in Savoy, IL. Cereal rye cover crop broadcastseeded September 23, 2014 into standing corn (Zea mays L.) any tillage or chemical application to suppress weed growth. Studies were included regardless of tillage (conservation vs. conventional tillage) or management (organic vs. conventional) system, although conservation tillage and organic systems were under-represented in the final data set (two studies for each system). A total of 17 studies fulfilled the search criteria; most were excluded because the search term weed retrieved studies examining the role of cover crops in suppressing weeds, not the use of weeds as a treatment comparison to cover crops. Other studies were culled because the measure of inorganic soil nitrogen occurred after cover crops and weeds had been terminated and incorporated into the soil (the decomposition of residues confounded estimates of potential nitrogen losses).

Leachate nitrogen and inorganic soil nitrogen are undoubtedly different measures of potential nitrogen loss.
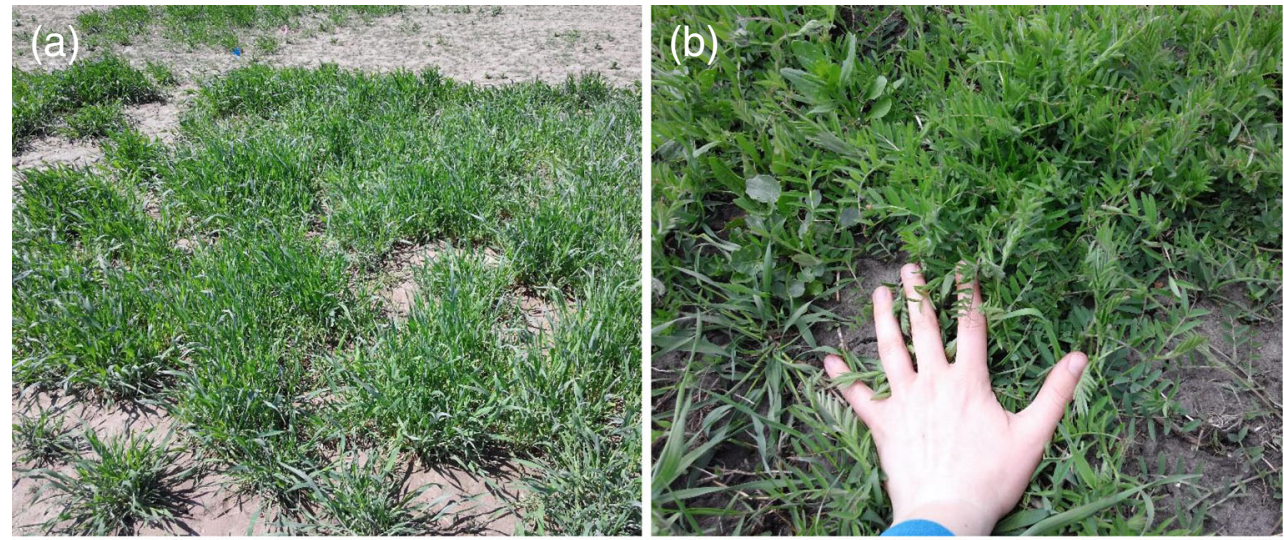

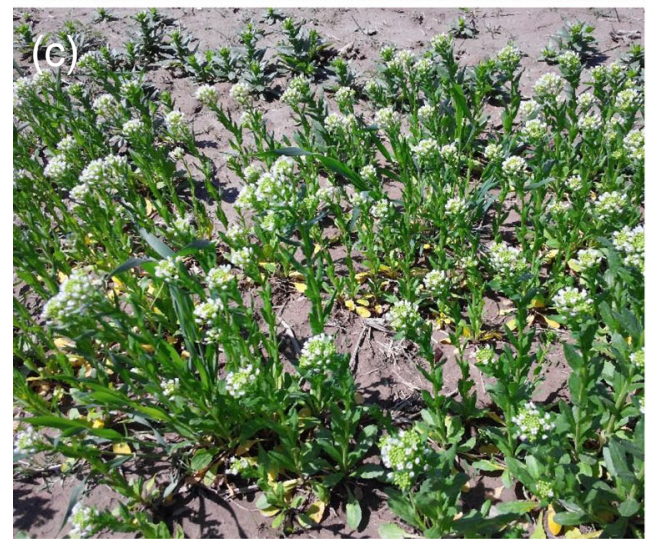

Fig. 2 Cereal rye (Secale cereale L.) (a) and hairy vetch (Vicia villosa L.) (b) cover crops, and ambient pennycress (Thlaspi arvense L.) (c) and henbit (Lamium amplexicaule L.) (d) weeds in Illinois. Cover crops

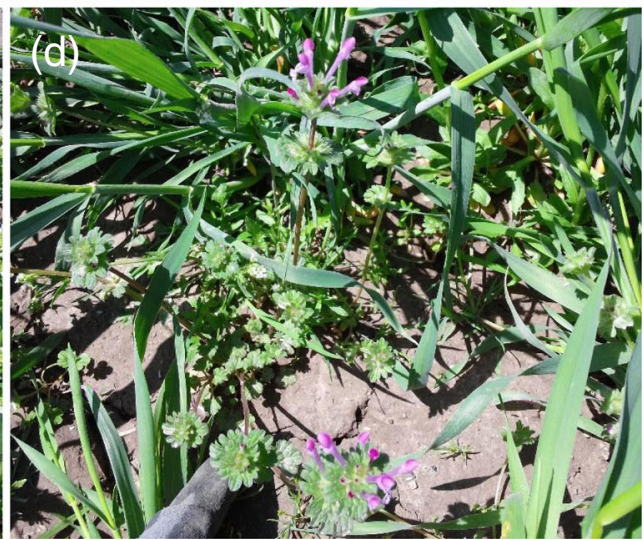

were planted in late-September 2014, and the photos were taken in lateApril 2015 at PrairiErth Farm and Kinnikinnick Farm near Atlanta and Roscoe, IL, respectively (photo credits: Ashley Holmes) 
The former estimates nitrogen concentrations in soil water beneath or near the bottom of the crop rooting zone via lysimeter, while the latter typically estimates inorganic nitrogen in bulk soil within the crop rooting zone via soil sampling and chemical extraction. Because elevated concentrations of inorganic soil nitrogen in the rooting zone precludes nitrogen leaching deeper in the profile, we elected to use the former as a proxy for future leaching potential given the lack of leachate data available within this literature search ( 7 of 17 studies eligible for data extraction). Macdonald et al. (2005) measured both inorganic soil nitrogen and cumulative leachate nitrogen, and regression analysis of their data suggests a positive correlation between measures $(p=0.003$ and $r=0.66)$. Moreover, preliminary analysis of data in this metaanalysis separated by measures of potential nitrogen loss (leachate nitrogen vs. inorganic soil nitrogen) resulted in similar trends among soil management treatments (albeit with larger confidence intervals due to the reduced number of observations). However, it is important to note that many soil and environmental factors will influence actual nitrogen loss via leaching and the relationship between leachate and inorganic soil nitrogen (e.g., precipitation, soil texture, soil organic matter content, plant species and growth stage, and residue cover).

\subsection{Data extraction and analysis}

Data for leachate or inorganic soil nitrogen, vegetative species and biomass, and soil texture were extracted from 17 studies (Table 1). Cumulative fallow period nitrogen leachate was the preferred response variable and was extracted when available; otherwise, a single time point estimate of nitrogen leachate or inorganic soil nitrogen was used. In cases where nitrogen data were presented graphically, data were extracted by using the Web Plot Digitizer v. 3.8 (http://arohatgi.info/WebPlotDigitizer). The species of cover crop and dominant weed species in the weedy fallow treatment were extracted from each study when available; cover crop species were later grouped by legumes and nonlegumes for analysis. In cases where mixtures of cover crops were planted, the treatment was grouped according to the dominant species in the mixture (e.g., a mixture of $70 \%$ nonlegume cover crops and $30 \%$ legume cover crops was grouped with nonlegumes for analysis). When available, weed and cover crop biomass data and soil texture data were extracted from the study, but this was not a requirement for inclusion in the meta-analysis.

A potential nitrogen loss response ratio was determined for each treatment in a study as cover crop or bare soil nitrogen/weedy fallow nitrogen. The natural $\log$ of this response ratio was calculated to linearize the ratio and improve normality given the small size of the data set (Hedges et al. 1999). Due to infrequent reporting of within-study error, response ratios were weighted according to the number $(n)$ of reps $\times$ sites $x$ years contributing to a paired mean observation as weight $=\left(n_{\text {cover }}\right.$ crop or bare soil $\left.\times n_{\text {weedy }}\right) /\left(n_{\text {cover crop }}\right.$ or bare soil $+n_{\text {weedy }}$ ) (Adams et al. 1997).

Bootstrap confidence intervals $(95 \%)$ were calculated for mean response ratios of interest (i.e., bare soil, legume cover crops, nonlegume cover crops, and all cover crops relative to weedy fallow) based on 4999 iterations by using the "boot" package in R (v. 3.1.3) (Adams et al. 1997). Response ratios for each group were considered significant if the bootstrap confidence interval did not overlap with zero and different from other groups if their bootstrap confidence intervals did not overlap. When possible, response ratios and confidence intervals were backtransformed and reported as a percent change in potential nitrogen loss (leachate or inorganic soil nitrogen) relative to weedy fallow for ease of interpretation. Lastly, a mixed-effect meta-regression model was used to explore possible relationships between the response ratio and cover crop biomass (a moderator of interest) (metafor package in $\mathrm{R}$ v. 3.1.3; Viechtbauer 2010). Heterogeneity of residuals was determined with a $Q_{E}$ statistic, and influence of the moderator was determined with an omnibus test and $Q_{M}$ statistic, both at a significance level of $\alpha=0.05$ (Viechtbauer 2010).

\section{Results and discussion}

\subsection{Weedy fallow and cover crops reduce potential nitrogen loss}

Potential nitrogen loss was $60 \%$ greater in bare soil compared to weedy fallow. Cover crops reduced potential nitrogen loss by $26 \%$ compared to weedy fallow (Fig. 3). Nonlegume cover crops were more effective than legumes in reducing potential nitrogen loss, and the effect was not significantly different between legumes and weedy fallow. Results of this meta-analysis suggest that weeds are effective nitrogen scavengers during fallow periods, but not as effective as nonlegume cover crops. In a similar meta-analysis of cover crops, Tonitto et al. (2006) found that compared to bare soil, nonlegume and legume cover crops reduced nitrogen leaching by 70 and $40 \%$, respectively. Interestingly, reduction in potential nitrogen loss by weedy fallow relative to bare soil $(60 \%)$ in this meta-analysis was greater than the benefits of legume cover crops (40\%) reported by Tonitto et al. (2006). Thus, evidence suggests that fallow weeds are just as effective as legume cover crops for reducing nitrogen loss from croplands. 


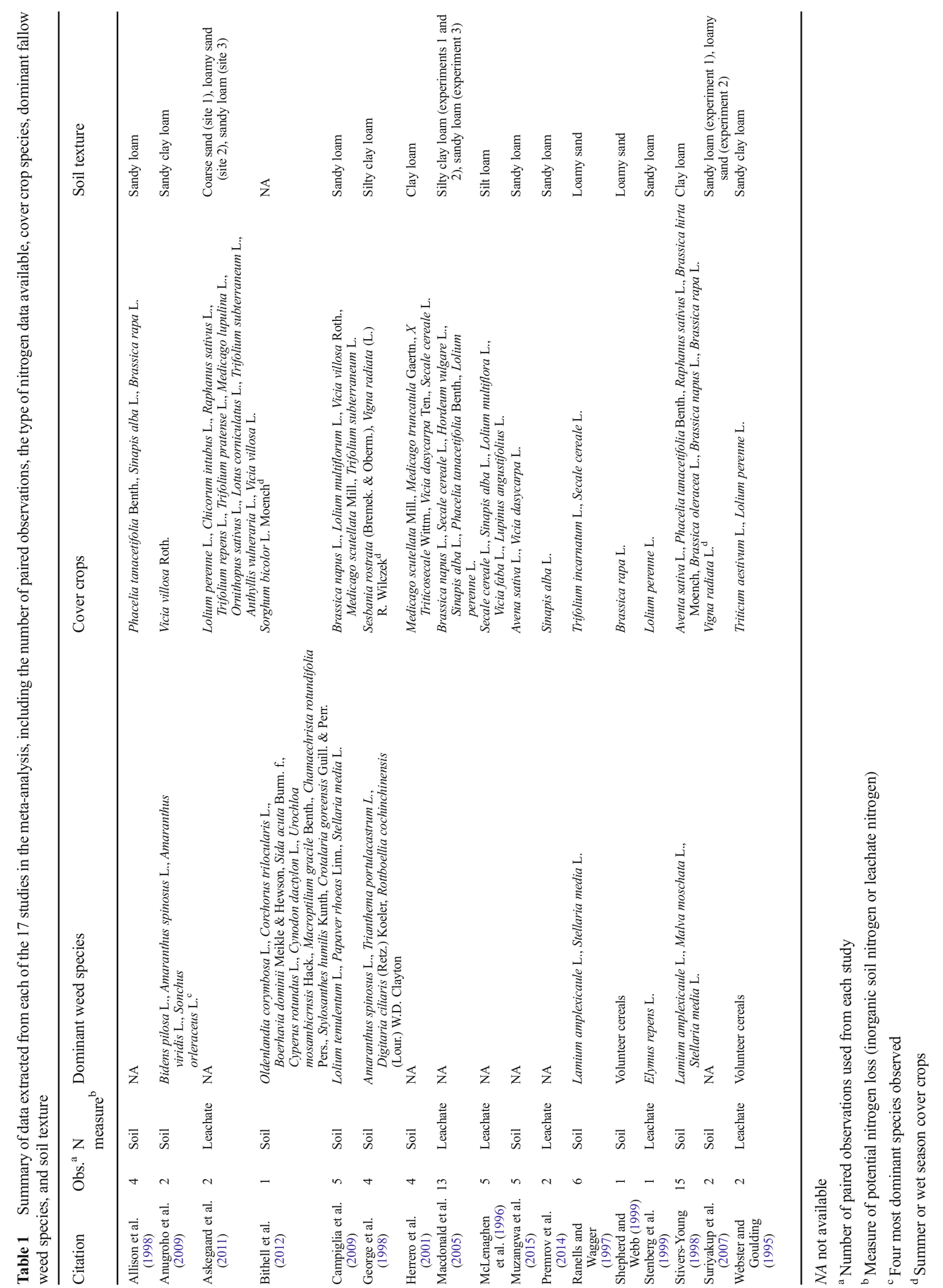




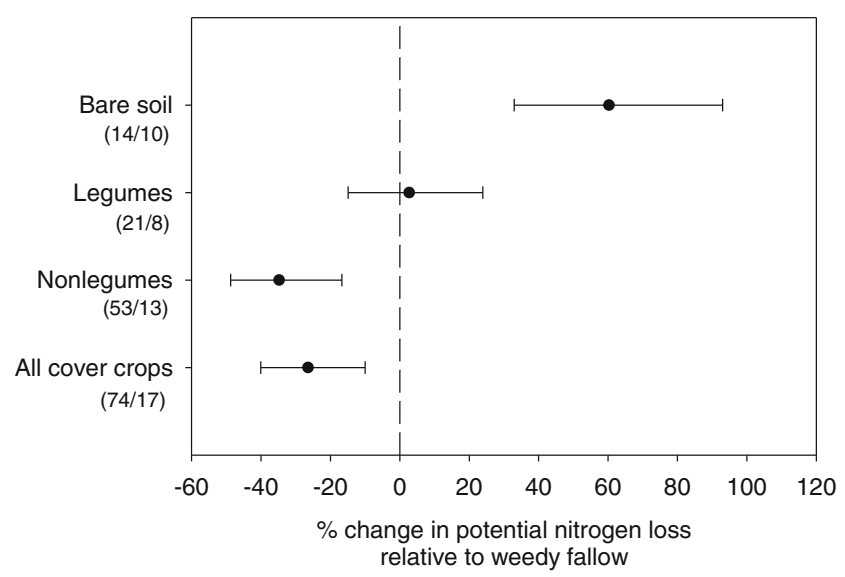

Fig. 3 Backtransformed mean effect of bare soil, legumes, nonlegumes, and all cover crop species on nitrogen leachate and inorganic soil nitrogen (potential nitrogen loss) relative to weedy fallow. Numbers in parentheses indicate number of observations/number of studies. Error bars represent backtransformed $95 \%$ bootstrap confidence intervals

\subsection{Increasing vegetative biomass may reduce potential nitrogen loss}

Meta-regression of the nitrogen response ratio versus cover crop biomass did not reveal a significant relationship, likely due in part to the small number of studies analyzed (Borenstein et al. 2009). However, visual inspection of the data suggests a possible negative relationship between cover crop biomass and nitrogen response ratio. In three of the five studies where weedy fallow was more effective than cover crops in reducing potential nitrogen loss (indicated by a natural log response ratio greater than zero), cover crop biomass was less than $1.9 \mathrm{Mg} \mathrm{ha}^{-1}$ (Fig. 4). In contrast, in all six of the studies where cover crops were as or more effective than weedy fallow in preventing potential nitrogen loss (as indicated by a natural log response ratio less than or equal to zero), cover crop biomass was greater than $1.9 \mathrm{Mg} \mathrm{ha}^{-1}$. While not conclusive, the data seem to suggest a logical relationship between primary productivity and nitrogen retention with a critical threshold near $2 \mathrm{Mg} \mathrm{ha}^{-1}$. Clark et al. (1997) found that biomass nitrogen of hairy vetch (Vicia villosa L.) and rye (Secale cereale L.) winter cover crops increased proportionally with time and that delaying cover crop termination until late spring (April) was necessary to achieve greater than $2 \mathrm{Mg} \mathrm{ha}^{-1}$ biomass.

\subsection{Options for increasing the benefits of weedy fallow}

Fallow weed biomass is often less than $2 \mathrm{Mg} \mathrm{ha}^{-1}$ because the distribution and abundance of weed seeds in croplands are heterogeneous and some weed species accumulate comparatively small amounts of biomass and corresponding tissue nitrogen. However, there may be opportunities to manage the weed seedbank for greater uniformity in the establishment of beneficial species. For example, eliminating fall weed

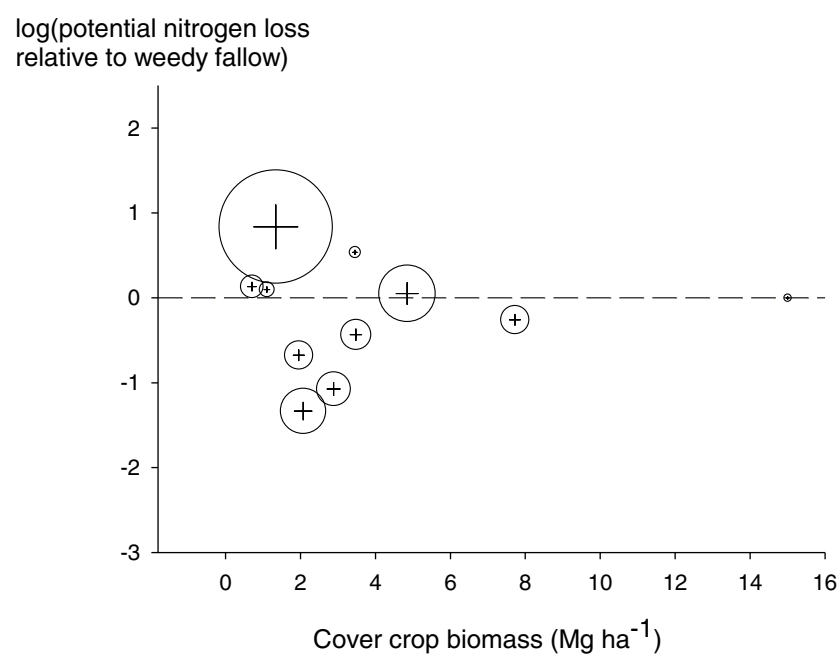

Fig. 4 Relationship between $\log$ (potential nitrogen loss relative to weedy fallow) and cover crop biomass. Bubble diameter is proportionate to the weight of each study in the meta-regression. The largest bubble represents 15 observations from Stivers-Young (1998), and the smallest bubble represents one observation from Bithell et al. (2012). $Q_{E}$ (test for residual heterogeneity) $=57.1, p<0.0001$; and $Q_{M}$ [test of the moderator (i.e., cover crop biomass) $]=0.002, p=0.96$

management and delaying spring weed management would allow time for weed seed production and accumulation of potentially desirable species within a field [e.g., T. arvense L. (pennycress)]. If necessary, a selective herbicide or physical disturbance (e.g., tillage or mowing) could be used to prevent seedbank accumulation of noxious or otherwise problematic weed species. Given the fecundity of most weed species and the potential for long-term seed viability in the soil (Roberts and Feast 1973), 1 or 2 years of this passive weed management approach would likely be enough to achieve long-term shifts in weed seedbank abundance and community composition (Menalled et al. 2001; Davis et al. 2005). Because management can have long-term impacts on weed seedbanks and future weed competition (Wortman et al. 2010), management of fallow weeds would need to be intentional with care taken to avoid unintended consequences.

A more direct approach to achieving a desirable, abundant, and uniform weedy fallow community would be to intentionally plant weed seed, like pennycress, to supplement the ambient weed seedbank. Pennycress is a common winter annual weed species in the MRB with potential to reduce nitrogen losses without deleterious effects on future crops. In fact, there have been recent efforts to commercialize pennycress as a cover crop and an oilseed bioenergy crop (Sedbrook et al. 2014), so intentionally seeding this weed may be viewed with less skepticism. Pennycress in the MRB typically germinates in autumn during crop maturity and senescence; leaves develop from a basal rosette, and cold vernalization is required to initiate vertical bolting, flower development, and seed production the following spring. In most cases, pennycress does not directly compete with corn, soybean (Glycine max [L.] Merr.), 
or other summer annual cash crops in the MRB. If pennycress seedbank abundance was supplemented one time and allowed to annually (or at least occasionally) regenerate, farmers might be able to achieve the equivalent of a self-reseeding cover crop (albeit with a traditional weed species) that is easy to manage and will not directly compete with cash crops. An additional benefit of increasing the abundance and uniformity of a single species like pennycress is to increase interspecific weed competition and suppression of undesirable weedy fallow species (e.g., Cirsium arvense L.).

One could argue that intentionally seeding a weed species like pennycress is not different from the typical use of cover crops. In many ways, it is not and the distinction of plants as weeds is arbitrary, but one advantage of using weedy plant biotypes versus improved cover crop cultivars is the presence of dormancy traits in weed seed that could contribute to a selfreseeding conservation strategy. Indeed, domesticated pennycress will germinate in warm soil conditions, but the weedy biotype will not (Hazebroek and Metzger 1990; Sedbrook et al. 2014). Most cover crop species that shed seed will likely compete with subsequent cash crops, but the life history traits of pennycress make it the ideal self-reseeding cover crop in summer annual cropping systems. The predictable presence of nitrogen scavenging plants with minimal effort is the distinct advantage of the weedy fallow strategy compared to planting cover crops. However, for the weedy fallow strategy to be successful, it would be imperative that species allowed to persist and produce seed did not germinate, grow, and directly compete with cash crops.

\subsection{Limitations of weedy fallow}

Evidence from this meta-analysis suggests that, in certain situations, naturally occurring weeds may provide an important ecosystem service in croplands. However, this is not to suggest that all fallow weeds should be allowed to persist in all cropping systems. The potential benefits of allowing fallow weeds to persist in the landscape are accompanied by potential pitfalls that should be carefully considered prior to implementing this practice.

First, the weedy fallow approach assumes that all crops in rotation have the same growth cycle (e.g., summer annual). This is true throughout most of the MRB where the cornsoybean rotation dominates croplands, but addition of a winter annual crop like wheat (Triticum aestivum L.) or a perennial forage crop like alfalfa (Medicago sativa L.) to the rotation would complicate the weedy fallow strategy. In a diverse rotation with multiple growth cycles represented (which is a best management practice; Davis et al. 2012), allowing fallow weeds to persist and possibly reproduce could contribute to future crop-weed interference. In these cases, cover crops would be a better nitrogen reduction tool because physiological development is more predictable and it is easier to prevent the unwanted contribution of cover crop "volunteers" to the seedbank. However, depending on the dominant weed species in the community, it may be possible to mitigate weed seed production by mowing, tillage, or herbicide application near the end of the fallow period. The most competitive and problematic weeds in corn-soybean systems of the MRB (e.g., Amaranthus spp., Setaria spp., and Ambrosia trifida L.) germinate in the late spring and early summer and shed seed prior to or at the time of harvest; thus, any herbicide applications or tillage after harvest are directed toward the management of perennial or winter annual weeds, most of which could be easily controlled at the end of the fallow period (the following spring) to prevent direct crop-weed interference.

Future crop-weed interference in diversified rotations could be especially problematic if the fallow weed community included herbicide-resistant populations. Several winter annual weed species (e.g., T. arvense L., L. amplexicaule L., and S. arvensis L. subsp. Arvensis) have developed resistance to one or more groups of herbicides, but none of these populations have been identified in the MRB where winter annual crop production is rare (Heap 2016). The lack of winter annual crop production or associated intensive chemical weed management during the winter fallow period likely contributes to reduced selection pressure toward herbicide-resistant winter annual weed populations in the MRB. The weedy fallow approach could similarly reduce selection pressure toward resistance and also serve as a refuge for susceptible populations (a potential genetic tool for mitigating herbicide-resistant weed populations on a landscape scale).

Weedy fallow could also have indirect negative effects on subsequent crops. Delayed management of winter annual weeds may reduce available water and nutrients in resourcelimited environments leading to reduced yield of the subsequent crop (Mueller et al. 2013). Similarly, some weed species (e.g., L. amplexicaule L.) can serve as hosts for pests like soybean cyst nematode, and weed management at the beginning of the fallow period is recommended to minimize the risk of infestation and yield loss in subsequent soybean crops (Werle et al. 2015). The indirect deleterious effects of weeds on cash crops are a legitimate limitation of weedy fallow, but many of these limitations also apply to cover crops. For example, winter annual cover crop residues (e.g., cereal rye) can sometimes reduce subsequent cash crop yields due in part to reduced soil water availability, nitrogen immobilization, cooler soil temperatures, allelopathy, or increased pest abundance (e.g., Sainju and Singh 2001).

One challenge of formalizing weedy fallow as a conservation strategy is the variability in weed seedbank, establishment, biomass, and nitrogen recovery among farms. Indeed, the nitrogen reduction potential of weeds is likely tied to primary productivity (e.g., Fig. 4), but the implementation of any conservation practice will result in a range of possible benefits that are influenced by farmer management and local soil and 
climatic conditions. For example, farmers are incentivized to grow cover crops through various conservation programs, but there is no oversight (only recommendations) to ensure that cover crops are planted early enough or terminated late enough to achieve desired conservation benefits. Thus, a farmer could receive incentive payments for seeding a cover crop at the last opportunity in autumn and terminate at the first opportunity in spring before the accumulation of any measurable benefits. Unfortunately, these low biomass cover crop management scenarios are relatively common despite evidence that most agronomic and ecological benefits of cover crops are positively correlated with biomass (Snapp et al. 2005). Evidence from this meta-analysis suggests that ambient weeds may be a better (or at least comparable) alternative to low biomass cover crop management (Fig. 4). Results also highlight the importance of managing cover crops for increased primary productivity and associated benefits.

Lastly, it is important to note that cover crops, depending on the species or mixture of species, can provide a number of benefits beyond nitrogen reduction, including nitrogen fixation, increased soil organic matter, weed suppression in subsequent crops, and suppression of soil borne diseases (Snapp et al. 2005). With the exception of nitrogen fixation, many common weed species of the MRB may have the capacity to provide some of the same ecosystem services, but there is currently a lack of research to demonstrate this potential.

\subsection{Policy implications and potential impact of weedy fallow}

The results of this meta-analysis and associated management and policy recommendations run contrary to the conventional paradigm, where weeds are often viewed and managed as a pest without utility. As a result, these conclusions will understandably be met with skepticism among farmers, researchers, conservationists, and policy-makers. However, farmers are often pragmatic, and the opportunity to passively implement a conservation practice without any additional input of time, labor, or money may have appeal, especially if it was financially incentivized through conservation programs. Nonetheless, stakeholder attitudes toward this concept will ultimately determine any changes in future behavior; thus, the concept of weedy fallow as a conservation practice should be presented to stakeholders with strong supporting evidence, acknowledgement of the limitations, and awareness of current attitudes toward weeds and nitrogen pollution issues in agriculture.

The USDA NRCS Conservation Stewardship Program (CSP) provides annual incentive-based payments to farmers for implementing new conservation enhancements or maintaining existing conservation practices. As the current CSP manual reads, weedy fallow is not a recognized conservation practice, but results from this study suggest that it should be given consideration (CSP 2015). Two existing conservation enhancements in the CSP that could potentially be modified to include weedy fallow are (1) "increase residue levels by $10 \%$ " and (2) "plant a grass-type cover crop that will scavenge nitrogen left in the soil after harvest of a previous crop." Unfortunately, living weeds do not count toward a $10 \%$ residue increase in this program. This distinction seems to encourage chemical weed management during the fallow period, despite the conservation benefits of fallow weeds revealed by this meta-analysis. Results also suggest that weedy fallow should be given consideration in CSP as a "[plant] that will scavenge nitrogen left in the soil after harvest of a previous crop." While the magnitude of nitrogen reduction in weedy fallow was less than with cover crops, the data still demonstrate significant potential for nitrogen loss when weeds are removed via tillage or herbicides during the fallow period (i.e., bare soil).

Given the relative ease of implementing weedy fallow, it may have greater potential than cover crops for net nitrogen reduction on a regional scale. Using the response ratios from this meta-analysis, consider the following scenario of weedy fallow adoption. If we estimate that the average bare soil fallow field in the MRB loses $100 \mathrm{~kg} \mathrm{~N} \mathrm{ha}^{-1}$ year $^{-1}$ (60\% greater than weedy fallow; Fig. 3), we would expect to lose $63 \mathrm{~kg}$ $\mathrm{N} \mathrm{ha}^{-1}$ year $^{-1}$ from the average weedy fallow field and $47 \mathrm{~kg}$ $\mathrm{N} \mathrm{ha}^{-1}$ year ${ }^{-1}$ from the average cover-cropped field (26\% less than weedy fallow; Fig. 3). Therefore, if weedy fallow were practiced on 4 million ha of cropland in the MRB (assuming a $5 \%$ adoption rate), the net nitrogen reduction relative to bare soil fallow would be 148 million $\mathrm{kg} \mathrm{N}_{\text {year }}{ }^{-1}$ in the MRB. Compare this to cover crops, which are currently used on approximately 1.6 million ha in the $\mathrm{MRB}(<2 \%$ adoption rate; Bryant et al. 2013); the net nitrogen reduction of cover crops relative to bare soil fallow would be 84.8 million $\mathrm{kg} \mathrm{N}$ year $^{-1}$ in the MRB.

\section{Conclusion}

Cover crops are an effective nitrogen reduction tool that can provide many additional agronomic and ecological benefits. Policy-makers and conservationists should continue to promote and incentivize cover crop use, especially in sandy soils most susceptible to nitrogen leaching (Gaines and Gaines 1994). However, given the barriers to adoption and relatively low current rates of cover crop use (Myers and Watts 2015), weedy fallow may be an alternative nitrogen reduction strategy with a greater potential for rapid on-farm adoption and net nitrogen reduction from annual cropping systems of the MRB and elsewhere. Conservation incentive programs should consider revising current policies to encourage farmers to grow all potentially beneficial fallow plants, including cover crops, crop volunteers, and weeds. 


\section{References}

Adams DC, Gurevitch J, Rosenberg MS (1997) Resampling tests for meta-analysis of ecological data. Ecology 78:1277-1283. doi:10.1890/0012-9658(1997)078[1277:RTFMAO]2.0.CO;2

Allison MF, Armstrong MJ, Jaggard KW, Todd AD (1998) Integration of nitrate cover crops into sugarbeet (Beta vulgaris) rotations. I. Management and effectiveness of nitrate cover crops. J Agr Sci 130:53-60

Anugroho F, Kitou M, Nagumo F et al (2009) Effect of the sowing date on the growth of hairy vetch (Vicia villosa) as a cover crop influenced the weed biomass and soil chemical properties in a subtropical region. Weed Biol Manag 9:129-136. doi:10.1111/j.14456664.2009.00330.x

Askegaard M, Olesen JE, Rasmussen IA, Kristensen K (2011) Nitrate leaching from organic arable crop rotations is mostly determined by autumn field management. Agric Ecosyst Environ 142:149160. doi:10.1016/j.agee.2011.04.014

Bithell SL, Hartley N, Martin CC et al (2012) Importance of a wet season cover crop to nitrate recovery in tropical vegetable production. Acta Hortic 958:105-112. doi:10.17660/ActaHortic.2012.958.11

Borenstein M, Hedges LV, Higgins JPT, Rothstein HR (2009) Meta-regression. In: Introduction to meta-analysis. John Wiley \& Sons, Ltd., pp 187-203

Bryant L, Stockwell R, White T (2013) Counting cover crops. http://www. nwf.org/News-and-Magazines/Media-Center/Reports/Archive/2013 /10-01-13-Counting-Cover-Crops.aspx. Accessed 10 Sept 2015

Burkart MR, James DE (1999) Agricultural-nitrogen contributions to hypoxia in the Gulf of Mexico. J Environ Qual 28:850. doi:10.2134/jeq1999.00472425002800030016x

Campiglia E, Paolini R, Colla G, Mancinelli R (2009) The effects of cover cropping on yield and weed control of potato in a transitional system. Field Crop Res 112:16-23. doi:10.1016/j.fcr.2009.01.010

Clark AJ, Decker AM, Meisinger JJ, McIntosh MS (1997) Kill date of vetch, rye, and a vetch-rye mixture: I. Cover crop and corn nitrogen. Agron J 89:427-434. doi:10.2134/agronj1997.00021962008900030010x

Conservation Stewardship Program [CSP], United States Department of Agriculture, Natural Resources Conservation Service (2015) h t t p : / / w w w. n r c s. u s d a gov/wps/portal/nrcs/main/national/programs/financial/csp/. Accessed 10 Sept 2015

David MB, Flint CG, McIsaac GF et al (2013) Biophysical and social barriers restrict water quality improvements in the Mississippi River basin. Environ Sci Technol 47:11928-11929. doi:10.1021 les403939n

Davis AS, Renner KA, Gross KL (2005) Weed seedbank and community shifts in a long-term cropping systems experiment. Weed Sci 53: 296-306

Davis AS, Hill JD, Chase CA et al (2012) Increasing cropping system diversity balances productivity, profitability and environmental health. PLoS One 7:e47149. doi:10.1371/journal.pone.0047149

Di HJ, Cameron KC (2002) Nitrate leaching in temperate agroecosystems: sources, factors and mitigating strategies. Nutr Cycl Agroecosys 64:237-256. doi:10.1023/A:1021471531188

Gaines TP, Gaines ST (1994) Soil texture effect on nitrate leaching in soil percolates. Commun Soil Sci Plan 25:2561-2570. doi:10.1080 /00103629409369207

George T, Buresh RJ, Ladha JK, Punzalan G (1998) Recycling in situ of legume-fixed and soil nitrogen in tropical lowland rice. Agron J 90. doi:10.2134/agronj1998.00021962009000030018x

Hazebroek JP, Metzger JD (1990) Seasonal pattern of seedling emergence, survival, and reproductive behavior in Thlaspi arvense (Cruciferae. Am J Bot 77:954-962

Heap I (2016) The international survey of herbicide resistant weeds. www.weedscience.org. Accessed 29 Jul 2016
Hedges LV, Gurevitch J, Curtis PS (1999) The meta-analysis of response ratios in experimental ecology. Ecology 80:1150-1156. doi:10.1890 /0012-9658(1999)080[1150:TMAORR]2.0.CO;2

Herrero EV, Mitchell JP, Lanini WT et al (2001) Use of cover crop mulches in a no-till furrow-irrigated processing tomato production system. HortTechnology 11:43-48

Macdonald AJ, Poulton PR, Howe MT et al (2005) The use of cover crops in cereal-based cropping systems to control nitrate leaching in SE England. Plant Soil 273:355-373. doi:10.1007/s11104-005-0193-3

McLenaghen RD, Cameron KC, Lampkin NH et al (1996) Nitrate leaching from ploughed pasture and the effectiveness of winter catch crops in reducing leaching losses. New Zeal J Agr Res 39:413-420. doi:10.1080/00288233.1996.9513202

Menalled FD, Gross KL, Hammond M (2001) Weed aboveground and seedbank community responses to agricultural management systems. Ecol Appl 11:1586-1601

Mueller ND, Ruiz Diaz DA, Dille JA et al (2013) Winter annual weed management and nitrogen rate effects on corn yield. Agron J 105: 1077. doi:10.2134/agronj2012.0344

Muzangwa L, Chiduza C, Muchaonyerwa P (2015) Bicultures of oat (Avena sativa) and grazing vetch (Vicia dasycarpa) regulate residue decomposition, nitrogen and phosphorus dynamics, and weed suppression in maize. Int J Agr Biol 17:475-482. doi:10.17957 /IJAB/17.3.14.233

Myers R, Watts C (2015) Progress and perspectives with cover crops: interpreting three years of farmer surveys on cover crops. J Soil Water Conserv 70:125A-129A

Power JF, Schepers JS (1989) Nitrate contamination of groundwater in North America. Agric Ecosyst Environ 26:165-187. doi:10.1016 /0167-8809(89)90012-1

Premrov A, Coxon CE, Hackett R et al (2014) Effects of over-winter green cover on soil solution nitrate concentrations beneath tillage land. Sci Total Environ 470-471:967-974. doi:10.1016/j. scitotenv.2013.10.057

Ranells NN, Wagger MG (1997) Nitrogen-15 recovery and release by rye and crimson clover cover crops. Soil Sci Soc Am J 61:943. doi:10.2136/sssaj1997.03615995006100030033x

Roberts HA, Feast PM (1973) Emergence and longevity of seeds of annual weeds in cultivated and undisturbed soil. J Appl Ecol 10: 133-143. doi:10.2307/2404721

Sainju UM, Singh BP (2001) Tillage, cover crop, and kill-planting date effects on corn yield and soil nitrogen. Agron J 93:878. doi:10.2134 /agronj2001.934878x

Sedbrook JC, Phippen WB, Marks MD (2014) New approaches to facilitate rapid domestication of a wild plant to an oilseed crop: example pennycress (Thlaspi arvense L. Plant Sci 227:122-132. doi:10.1016 /j.plantsci.2014.07.008

Shepherd M, Webb J (1999) Effects of overwinter cover on nitrate loss and drainage from a sandy soil: consequences for water management? Soil Use Manage 15:109-116. doi:10.1111/j.14752743.1999.tb00073.x

Snapp SS, Swinton SM, Labarta R et al (2005) Evaluating cover crops for benefits, costs and performance within cropping system niches. Agron J 97:322-332. doi:10.2134/agronj2005.0322

Staver KW, Brinsfield RB (1998) Using cereal grain winter cover crops to reduce groundwater nitrate contamination in the mid-Atlantic coastal plain. J Soil Water Conserv 53:230-240

Stenberg M, Aronsson H, Lindén B et al (1999) Soil mineral nitrogen and nitrate leaching losses in soil tillage systems combined with a catch crop. Soil Till Res 50:115-125. doi:10.1016/S0167-1987(98)00197-4

Stivers-Young L (1998) Growth, nitrogen accumulation, and weed suppression by fall cover crops following early harvest of vegetables. Hortscience 33:60-63

Suriyakup P, Polthanee A, Pannangpetch K et al (2007) Introducing mungbean as a preceding crop to enhance nitrogen uptake and yield 
of rainfed rice in the north-east of Thailand. Aust J Agric Res 58: 1059-1067. doi:10.1071/AR06309

Tonitto C, David MB, Drinkwater LE (2006) Replacing bare fallows with cover crops in fertilizer-intensive cropping systems: a meta-analysis of crop yield and N dynamics. Agric Ecosyst Environ 112:58-72. doi:10.1016/j.agee.2005.07.003

Viechtbauer W (2010) Conducting meta-analyses in R with the metafor package. J Stat Softw 36:1-48

Webster CP, Goulding KWT (1995) Effect of one year rotational set-aside on immediate and ensuing nitrogen leaching loss. Plant Soil 177: 203-209. doi:10.1007/BF00010126

Werle R, Giesler LJ, Bernards ML, Lindquist JL (2015) Likelihood of soybean cyst nematode (Heterodera glycines) reproduction on henbit (Lamium amplexicaule) roots in Nebraska. Weed Tech 29: 35-41. doi:10.1614/WT-D-14-00063.1

Wortman SE, Lindquist JL, Haar MJ, Francis CA (2010) Increased weed diversity, density and above-ground biomass in long-term organic crop rotations. Renew Agr Food Syst 25:281-295. doi:10.1017 /S174217051000030X

Wyland LJ, Jackson LE, Chaney WE, Klonsky K, Koike ST, Kimple B (1996) Winter cover crops in a vegetable cropping system: impacts on nitrate leaching, soil water, crop yield, pests and management costs. Agric Ecosyst Environ 59:117. doi:10.1016/0167-8809(96)01048-1

Xing GX, Zhu ZL (2000) An assessment of N loss from agricultural fields to the environment in China. Nutr Cycl Agroecosys 57:67-73. doi:10.1023/A:1009717603427 